\title{
QUALIDADE PÓS-COLHEITA DE ARAÇÁ-VERMELHO
}

\section{POSTHARVEST QUALITY OF RED STRAWBERRY-GUAVA}

\author{
Janaína Muniz ${ }^{1}$, Tânia Regina Pelizza ${ }^{2}$, Ana Paula Fernandes de Lima ${ }^{3}$, Mayra Juline Gonçalves ${ }^{4}$, Leo Rufato ${ }^{5}$
}

\begin{abstract}
${ }^{1}$ Economista, Dra. em Produção Vegetal, Técnica de Laboratório em Biotecnologia no Instituto Federal de Educação, Ciência e Tecnologia (IFSC) - Câmpus Lages/SC, e-mail: janaina.muniz@ifsc.edu.br; ${ }^{2}$ Engenheira Agrônoma, Dra. em Ciências, Área de Concentração: Fruticultura de Clima Temperado - UFPel/FAEM - Pelotas/RS, e-mail: trpelizza@yahoo.com.br; ${ }^{3}$ Engenheira Agrônoma, Dra. em Ciências, Área de Concentração: Fruticultura de Clima Temperado - UFPel/FAEM - Pelotas/RS, e-mail: apflima88@gmail.com; ${ }^{4}$ Bióloga, Dra. em Produção Vegetal, Bolsista de Pós-Graduação PNPD/CAPES do Programa de Pós-Graduação em Produção Vegetal da Universidade do Estado de Santa Catarina, CAV/UDESC - Lages/SC, e-mail: mayra. juline@hotmail.com; ${ }^{5}$ Engenheiro Agrônomo, Dr. em Ciências, Área de Concentração: Fruticultura de Clima Temperado, Professor Adjunto do Curso de Agronomia na área de Fruticultura de Clima Temperado na Universidade do Estado de Santa Catarina, CAV/UDESC - Lages/SC, e-mail: leoruffato@yahoo.com.br
\end{abstract}

Rev. U.D.C.A Act. \& Div. Cient. 20(2): 311-319, Julio-Diciembre, 2017

\section{RESUMO}

O objetivo deste trabalho foi avaliar o efeito de diferentes temperaturas e períodos de armazenamento nos atributos físico químicos de frutos de araçazeiro-vermelho. Esta pesquisa foi desenvolvida na Universidade do Estado de Santa Catarina (CAV/UDESC), em Lages (SC), Brasil, com frutos colhidos em fevereiro de 2016. O delineamento experimental foi inteiramente casualizado, com quatro repetições de 20 frutos, em esquema fatorial $2 \times 5$, com duas temperaturas $\left(2^{\circ} \mathrm{C}\right.$ e $\left.25^{\circ} \mathrm{C} \pm 2^{\circ} \mathrm{C}\right)$ e cinco períodos de armazenamento (0, 3, 6, 9 e 12 dias). As variáveis analisadas foram: perda de sólidos solúveis, acidez titulável, relação sólidos solúveis/acidez titulável, pH e vitamina C de araçávermelho. Ocorreu perda de massa dos frutos, em ambas as temperaturas, ao longo do período de armazenamento. O teor de sólidos solúveis aumentou em frutos armazenados à $2^{\circ} \mathrm{C}$. Observou-se ponto de mínima $(1,83 \%)$, para o teor de acidez titulável, em frutos armazenados a $25^{\circ} \mathrm{C}$. Para o $\mathrm{pH}$ dos frutos, oobservou-se ponto de mínima $(3,17)$ em temperatura de $2^{\circ} \mathrm{C}$ e ponto de máxima $(3,21)$, para aqueles armazenadconservados a $25^{\circ} \mathrm{C}$. Frutos em temperatura de $2^{\circ} \mathrm{C}$ apresentaram menor teor de vitamina $\mathrm{C}$ aos sete dias

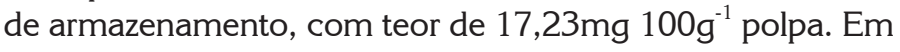
temperatura de $25^{\circ} \mathrm{C}$, observou-se menor teor de vitamina $\mathrm{C}$ aos seis dias, com teor de $26,69 \mathrm{mg} 100 \mathrm{~g}^{-1}$ polpa. Com a realização deste trabalho, pode-se concluir que, o uso de refrigeração a $2^{\circ} \mathrm{C}$, por até 12 dias, apresenta-se como uma alternativa de conservação de araçá-vermelho, mantendo-se as principais características físico-químicas dos frutos.

\section{SUMMARY}

The objective of this work was to evaluate the effect of different temperatures and storage periods on the physicchemical attributes of red gooseberries fruits. This research was carried out at the State University of Santa Catarina (CAV / UDESC), in Lages (SC), Brazil, with fruits harvested in February, 2016. The experimental design was completely randomized with four replicates of 20 fruits each, in a $2 \times 5$ factorial radomized, with two temperatures $\left(2^{\circ} \mathrm{C}\right.$ and $25^{\circ} \mathrm{C} \pm$ $2^{\circ} \mathrm{C}$ ) and five storage periods ( $0,3,6,9$ and 12 days). The analyzed variables were: mass loss, soluble solids, titratable acidity, soluble solubility/titratable acidity ratio, $\mathrm{pH}$ and vitamin C. Fruit mass loss occurred at both temperatures throughout the storage period. Soluble solids content increased in fruits at $2^{\circ} \mathrm{C}$. A minimum point $(1.83 \%)$ was observed for titratable acidity in fruits packed at $25^{\circ} \mathrm{C}$. A minimum point was observed $(3.17 \%)$ for the $\mathrm{pH}$ of the fruits at $2^{\circ} \mathrm{C}$ and maximum point $(3,21)$ for fruits at $25^{\circ} \mathrm{C}$. Fruits at $2^{\circ} \mathrm{C}$ presented lower vitamin $\mathrm{C}$ content in seven days of storage, with $17.23 \mathrm{mg} 100 \mathrm{~g}-1$ pulp. At $25^{\circ} \mathrm{C}$, a lower vitamin $C$ content was observed at day six, with a content of $26.69 \mathrm{mg}$ $100 \mathrm{~g}-1$ pulp. With the accomplishment of this work, it can be concluded that, the use of refrigeration at $2^{\circ} \mathrm{C}$, for up to 12 days, presents itself as an alternative for the conservation of red-gooseberries fruits, remaining the main physicochemical characteristics of the fruits.

Key words: Psidium cattleianum Sabine, Mirtaceae, conservation, storage, temperature.

Palavras-chave: Psidium cattleianum Sabine, amadurecimento, conservação, temperatura. 


\section{RESUMEN}

El objetivo de este trabajo fue evaluar el efecto de diferentes temperaturas y períodos de almacenamiento en los atributos físico-químicos de frutos de arazá. El diseño experimental utilizado fue completamente aleatorizado, con cuatro repeticiones, de 20 frutos, en un factorial $2 \times 5$, con temperaturas de $2^{\circ} \mathrm{C}$ y $25^{\circ} \mathrm{C} \pm 2^{\circ} \mathrm{C}$ y períodos de almacenamiento de 0, 3, 6 y 12 días. Las variables analizadas fueron: pérdida de peso de los frutos, sólidos solubles, acidez total titulable, relación de sólidos solubles y acidez titulable (índice de madurez), pH y vitamina C de los frutos. La concentración de sólidos solubles aumenta en los frutos almacenados a $2^{\circ} \mathrm{C}$. Se observó un punto de mínima para la acidez total titulable en los frutos almacenados a temperatura de $25^{\circ} \mathrm{C}(1,83 \%)$; un punto mínimo $(3,17)$, para el $\mathrm{pH}$ de los frutos en temperatura de $2^{\circ} \mathrm{C}$ y un punto máximo $(3,21)$, para los frutos sometidos a la temperatura de $25^{\circ} \mathrm{C}$. Frutos en temperatura de $2^{\circ} \mathrm{C}$ presentan menor contenido de vitamina $\mathrm{C}$, a los siete días de almacenamiento, con contenidos de $17,23 \mathrm{mg} 100 \mathrm{~g}^{-1}$ de pulpa. A temperatura de $25^{\circ} \mathrm{C}$, se observa menor concentración de vitamina $\mathrm{C}$, a los seis días, con contenidos de $26,69 \mathrm{mg} 100 \mathrm{~g}^{-1}$ pulpa. La refrigeración de frutos de arazá a $2^{\circ} \mathrm{C}$, se muestra como una alternativa de uso prometedora, para la conservación, hasta 12 días, por presentar mejores condiciones, para la manutención de las principales variables físico-químicas estudiadas.

Palabras clave: Psidium cattleianum Sabine, Mirtaceae, maduración, conservación, temperatura.

\section{INTRODUÇÃO}

O Brasil reflete a sua enorme riqueza de flora e fauna pois abriga a maior biodiversidade do planeta expressa pela reflete a sua enorme riqueza de flora e fauna em seus diferentes biomas pois (Brasil, 2017). .Além disso, muitas das espécies brasileiras são endêmicas, e diversas espécies de plantas de importância econômica mundial, dentre elas algumas frutíferas, são originárias do Brasil (Brasil, 2017).

Em trabalho conduzido com a finalidade de registrar a diversidade das angiospermas no Brasil, Zappi et al. (2015), relatam que houve um crescimento considerável, entre os anos 2010 e 2015, no número de espécies e nas taxas de endemismo para a maioria dos biomas (Caatinga, Cerrado, Floresta Atlântica, Pampa e Pantanal). Ainda, conforme os autores, dez famílias botânicas destacam-se como sendo as mais importantes na taxa de endemismo do país (62,3\%), dentre elas, está inclusa a família Myrtaceae. Dentro dos Biomas brasileiros, a Floresta Atlântica, em função de um grande número de espécies, tem um papel importante sobre a diversidade das angiospermas e é um centro de diversidade importante para as espécies desta família botânica (Zappi et al. 2015).

A evolução econômica e a demanda dos mercados reforçam o interesse de diversos países, como os latino-americanos, para as frutas em geral e as frutas nativas ou exóticas em particular (Costa et al. 2009). Há um grande campo potencial a ser explorado com diversas espécies frutíferas ainda pouco conhecidas, seja no mercado interno ou externo, como é o caso das frutíferas nativas, o que é referenciado por (Giacobbo et al. (2008) que destaca espécies da família Myrtaceae, como o araçá (Psidium spp.), a pitanga (Eugenia uniflora) e a feijoa (Acca sellowiana).

Espécies do gênero Psidium apresentam potencial econômico, principalmente na alimentação, pois seus frutos possuem um sabor exótico, alto teor de vitamina $\mathrm{C}$ e boa aceitação pelos consumidores (Franzon et al. 2009). Ainda, além do consumo in natura dos frutos, tais espécies podem ser exploradas pela agroindústria para sucos e para uso na fabricação de sorvetes, geleias, licores e outros produtos. De acordo com Bezerra et al. (2006), a exploração do araçazeiro se dá por extrativismo em áreas naturais e pomares domésticos. Assim, seus subprodutos são produzidos de forma artesanal em pequenas unidades de base familiar e comercializados apenas nas localidades próximas de seu local de produção.

Atualmente, no Brasil, as espécies com maior interesse para exploração comercial dos seus frutos são Psidium guineense Swartz (morfotipo amarelo) e Psidium cattleyanum Sabine (morfotipo vermelho) (Bezerra et al. 2006). .Conforme os autores, $P$. cattleyanum é originária do Sul do Brasil e distribuída do Rio Grande do Sul até a Bahia e seus frutos são considerados dos melhores entre as espécies de araçás.

Estudos recentes com $P$. cattleianum constataram que, nos extratos dessa espécie, há a presença de taninos, flavonoides e triterpenoides, com atividades antioxidantes (Scur et al. 2016) e antimicrobianas (Scur et al. 2016; Buso-Ramos et al. 2017). Além destes, estão presentes metabólitos secundários, como por exemplo, catequinas, saponinas, antraquinonas, taninos, glicosídeos, esteroides e compostos fenólicos (Faleiro et al. 2016).

A importância da conservação das frutas em pós-colheita está na necessidade de que as mesmas estejam em condições aceitáveis para abastecer o mercado consumidor (Cenci, 2006). Nesse sentido, segundo o autor, devem ser mantidas adequadas às características físicas, nutricionais, organolépticas e de segurança do alimento, o que reflete em sua qualidade final. De acordo com Drehmer \& Amarante (2008), o araçá-vermelho apresenta alta perecibilidade 
em condições de temperatura ambiente. Dessa forma, os autores indicam o armazenamento dos frutos a temperaturas próximas de $0^{\circ} \mathrm{C}$, a fim de se preservar a qualidade póscolheita dos mesmos.

O armazenamento refrigerado tem sido o método mais indicado, por sua eficácia na manutenção da qualidade póscolheita de frutos (Chitarra \& Chitarra, 2005). De acordo com os autores, este consiste em remover e minimizar a geração de calor dos produtos a serem conservados por meio da diminuição da intensidade da atividade respiratória, produção de etileno e ação de enzimas degradativas e oxidativas. Quando se trata de conservação em pós-colheita de frutas, de acordo com Abreu et al. (1998) é necessário que se tenha subsídios técnicos que visem à ampliação do tempo de armazenamento, evitando que ocorra alterações nas características físicas, organolépticas e nutricionais dos frutos.

Desta forma, conduziu-se este trabalho com o objetivo de avaliar a influência de diferentes temperaturas e períodos de armazenamento nos atributos físico-químicos de frutos de araçazeiro-vermelho.

\section{MATERIAL E MÉTODOS}

Os frutos de araçazeiro-vermelho foram colhidos no fevereiro de 2016, no período da manhã, no pomar didático de plantas nativas do Centro de Ciências Agroveterinárias, na Universidade do Estado de Santa Catarina (CAV/UDESC), em Lages, no estado de Santa Catarina, Brasil.

Os araçás-vermelho foram colhidos diretamente em bandejas de polietileno, sendo posteriormente levados no Laboratório do Núcleo de Tecnologia de Alimentos (NUTA) da instituição.

Em seguida, as bandejas com os frutos, foram envoltas com filme de policloreto de vinila (PVC) de $9 \mu \mathrm{m}$, pesadas em balança semi-analítica, Eletronic Balance Lutron ${ }^{\circledR}$, com precisão de $\pm 0,05 \mathrm{~g}$ e acondicionadas em incubadora DBO (Demanda Bioquímica de Oxigênio), Eletrolab ${ }^{\circledR}$, sob diferentes temperaturas, conforme estabelecido os tratamentos.

O delineamento experimental utilizado foi o inteiramente casualizado com quatro repetições de 20 frutos por parcela. Efetuou-se esquema fatorial $2 \times 5$, onde as temperaturas corresponderam a $2^{\circ} \mathrm{C}$ e $25^{\circ} \mathrm{C} \pm 2^{\circ} \mathrm{C}$ e os períodos de armazenamento de 0, 3, 6, 9 e 12 dias após a colheita dos frutos.

As variáveis analisadas foram:

- Perda de massa (g): obtida pela diferença entre a massa inicial e a massa ao final do período de armazenamento.
- Sólidos solúveis ( ${ }^{\circ}$ Brix): obtido a partir de leituras efetuadas com refratômetro portátil digital de bancada, modelo RTD-45, Digital Refractometer ${ }^{\circledR}$, com correção de temperatura para $20^{\circ} \mathrm{C}$.

- Acidez titulável (\% de ácido cítrico): obtida pela neutralização da solução de $10 \mathrm{~mL}$ de suco da polpa em $10 \mathrm{~mL}$ de água com $\mathrm{NaOH}$ a $0,1 \mathrm{~N}$.

- Relação sólidos solúveis e acidez total titulável (SS/AT).

- pH dos frutos: obtido através de medidas efetuadas com peagâmetro digital de bancada, Tecnopon ${ }^{\circledR}$, modelo mPA - 210P, versão 7.1).

- Vitamina C (mg de ácido ascórbico/100 $\mathrm{g}^{-1}$ de polpa):determinada por titulação direta com solução de Tillmans (Strohecker \& Henning, 1967). Foram misturados e homogeneizados, $10,0 \mathrm{~mL}$ de suco dos frutos, $30 \mathrm{~mL}$ de ácido oxálico a $5 \%$ refrigerado e 60 $\mathrm{mL}$ de água destilada. Posteriormente, após a filtragem da solução, retirou-se $5 \mathrm{~mL}$ da mesma e colocouse em erlenmeyer de $125 \mathrm{~mL}$, completando-se com água destilada até $50 \mathrm{~mL}$, posteriormente titulou-se com a solução de Tillmans refrigerada, até o ponto de viragem levemente róseo, persistindo a coloração por 15 segundos.

Os resultados obtidos foram submetidos à análise de variância (ANOVA) e quando significativos foram expressos através de regressão polinomial por meio do programa estatístico Winstat 2.0 (Machado \& Conceição, 2003).

\section{RESULTADOS E DISCUSSÃO}

Foram observadas diferenças significativas, em ambas as temperaturas, para a variável perda de massa ao longo do período de armazenamento, por meio de regressão linear decrescente (Figura 1). A perda de massa dos frutos de araçazeiro foi baixa, ao final de 12 dias de armazenamento, onde foram observados valores médios de $1,02 \mathrm{~g}(10,1 \%)$ e $0,90 \mathrm{~g}(8,9 \%)$ de redução da massa dos frutos, para as temperaturas de $2^{\circ} \mathrm{C}$ e $25^{\circ} \mathrm{C}$, respectivamente.

Carneiro et al. (2015) verificaram que frutos de cagaita, Eugenia dysenterica (Mirtaceae), apresentaram perda significativa de massa fresca ao longo do período de armazenamento (5 dias), onde frutos armazenados à temperatura de $5^{\circ} \mathrm{C}$ apresentaram menor perda de massa que frutos submetidos ao armazenamento em temperatura de $25^{\circ} \mathrm{C}$. Em um trabalho de revisão, conduzido por Parra-Coronado (2014) com goiabas, Psidium guajava L., (Mirtaceae), são relatados diferentes valores obtidos quanto à perda de massa e firmeza das frutas e que estas estão em função da temperatura de armazenamento e da cultivar avaliada. Em trabalho conduzido por Machado et al. (2007) com jabuticabas armazenadas em diferentes condições em saco plástico de $15 \mu \mathrm{m}$ de espessura e com perfurações de 


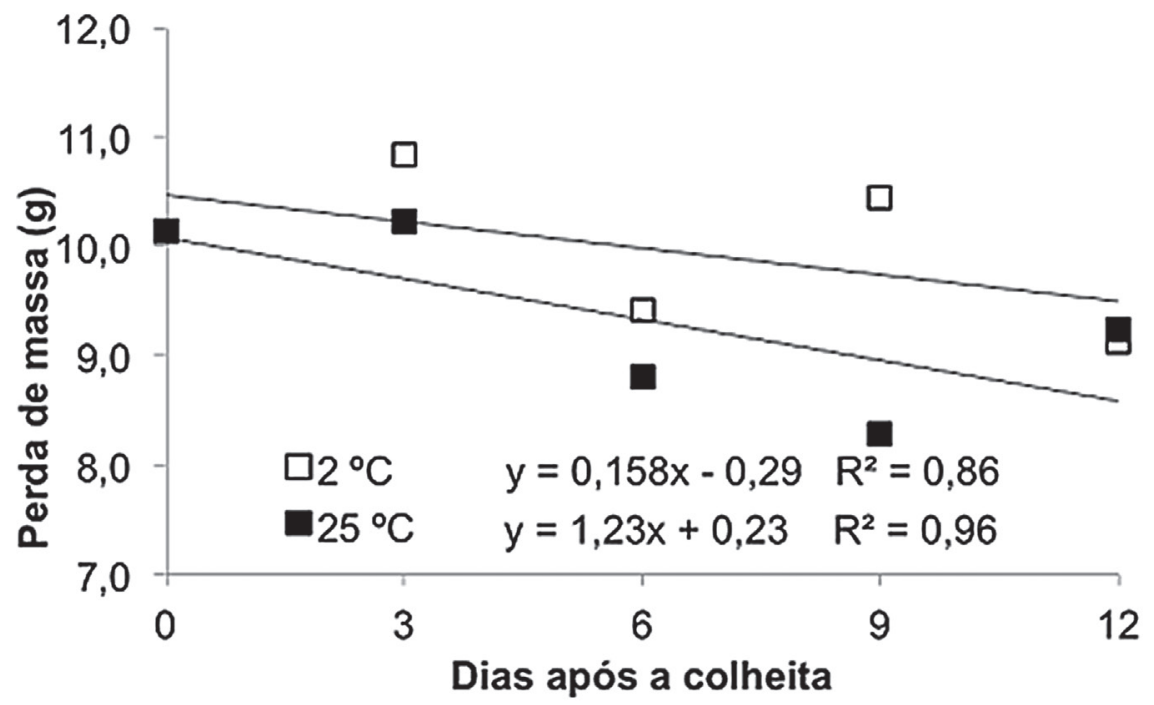

Figura 1. Perda de massa ( $\mathrm{g}$ ) dos frutos de araçazeiro-vermelho, em diferentes períodos (0, 3, 6, 9 e 12 dias) e temperaturas de armazenamento $\left(2^{\circ} \mathrm{C}\right.$ e $\left.25^{\circ} \mathrm{C}\right)$. CAV/UDESC, Lages, 2017.

0,5mm, perceberam expressiva perda de massa nos frutos. Mota et al. (2002) justifica a perda de massa em frutos de jabuticaba ao longo de um período de armazenamento devido à perda de água por transpiração, em função de que estas apresentam rápida deterioração pós-colheita. Além disso, os autores afirmam que jabuticabeiras submetidas à armazenagem em condição ambiente têm o processo de senescência iniciado rapidamente com o amadurecimento dos frutos, o que resulta na aceleração do processo respiratório e de perda de água.

Observou-se comportamento linear decrescente quanto aos teores de sólidos solúveis nos frutos armazenados a $2^{\circ} \mathrm{C}$ enquanto que não foi verificada diferença significativa ao longo do período de armazenamento para frutos submetidos a $25^{\circ} \mathrm{C}$ (Figura 2).

Lederman et al. (1997) verificaram uma variação de 14,5 a $17,0^{\circ}$ Brix em frutos de araçazeiro-amarelo. Pinto et al. (2000) obtiveram uma variação de 11,5 a $13,0^{\circ}$ Brix em frutos de araçazeiro-vermelho. Franco (1999) cita 11Bix em araçás. Valores esses, semelhantes aos encontrados nesse trabalho. Drehmer \& Amarante (2008) analisaram frutos de araçazeiro vermelho em dois estádios de maturação armazenados a $0^{\circ} \mathrm{C}$ e $20^{\circ} \mathrm{C}$ e concluíram que o teor de sólidos solúveis é afetado pelo estádio de maturação do mesmo, sendo inferior em frutos colhidos no estádio verde, independentemente da temperatura em que estes são armazenados. Tal condição reflete em um fruto que mantêm a qualidade pós-colheita quando armazenados sob refrigeração durante o tempo de prateleira. Em trabalho conduzido por Amarante et al. (2009) observaram que, para o acondicionamento de frutos de araçá-vermelho em diferentes embalagens plásticas, ocorreram diferenças na concentração de açúcares (SS), quando estas são armazenados à temperatura de $10^{\circ} \mathrm{C}$. Nesta condição, os teores médios de sólidos solúveis observados foram de 8,7 $7^{\circ}$ Brix, valor este bastante inferior ao observado no presente trabalho. De acordo com Machado et al. (2007) o teor de sólidos solúveis de frutas de jabuticabas armazenadas em bandejas plásticas com duas perfurações de $1 \mathrm{~mm}$ cada, na tampa, submetidas a oito dias sob refrigeração a $0^{\circ} \mathrm{C}$ e $90 \%$ de umidade relativa e mais dois dias em condições ambiente (temperatura de $20-22^{\circ} \mathrm{C}$ e 65 $70 \%$ de umidade relativa) foram de $15,44^{\circ}$ Brix, ao final do armazenamento. Conforme Carneiro et al. (2015) há uma redução nos teores de açúcares solúveis em frutos de cagaita (E. dysenterica), ao longo dos cinco dias de armazenamento, tanto para frutos armazenados à temperatura de $5^{\circ} \mathrm{C}$ como para aqueles armazenados à temperatura de $25^{\circ} \mathrm{C}$.

Para a variável acidez titulável verificou-se uma regressão quadrática com ponto de mínima (1,83\%), no sexto dia de armazenamento, em frutos conservados em temperatura de $25^{\circ} \mathrm{C}$. Não foi observada diferença significativa em frutos de araçá-vermelho submetidos à temperatura de armazenamento de $2^{\circ} \mathrm{C}$ (Figura 3 ).

Franco (1999) verificou valores de 1,87\% de ácido cítrico em em Psidium guineense (araçá amarelo). Enquanto que, Lederman et al. (1997), na coleção de germoplasma de Araçazeiro do IPA, com frutos de $P$. guineense colhidos durante a estação seca da Zona da Mata de Pernambuco, verificaram que a acidez teve uma variação de 0,95 a 1,31\%. Já, Pinto et al. (2000) citam uma variação de 1,52 a 2,29\% 


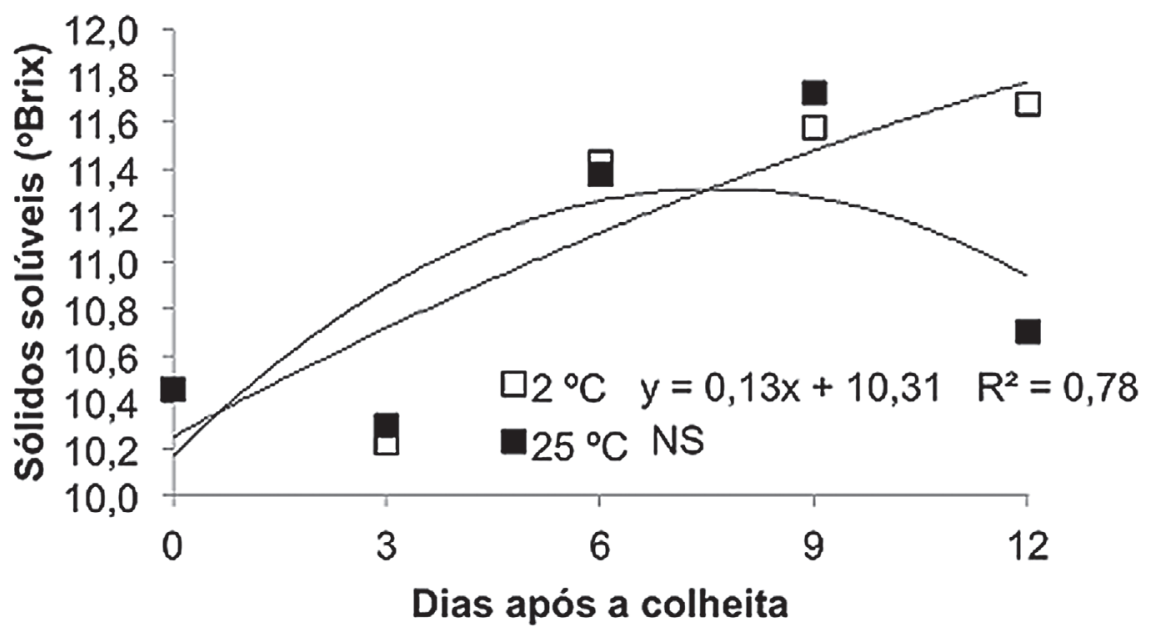

Figura 2. Teor de sólidos solúveis ( ${ }^{\circ}$ Brix) dos frutos de araçazeiro-vermelho, em diferentes períodos (0, 3, 6, 9 e 12 dias) e temperaturas de armazenamento $\left(2^{\circ} \mathrm{C}\right.$ e $\left.25^{\circ} \mathrm{C}\right)$. CAV/UDESC, Lages, 2017.

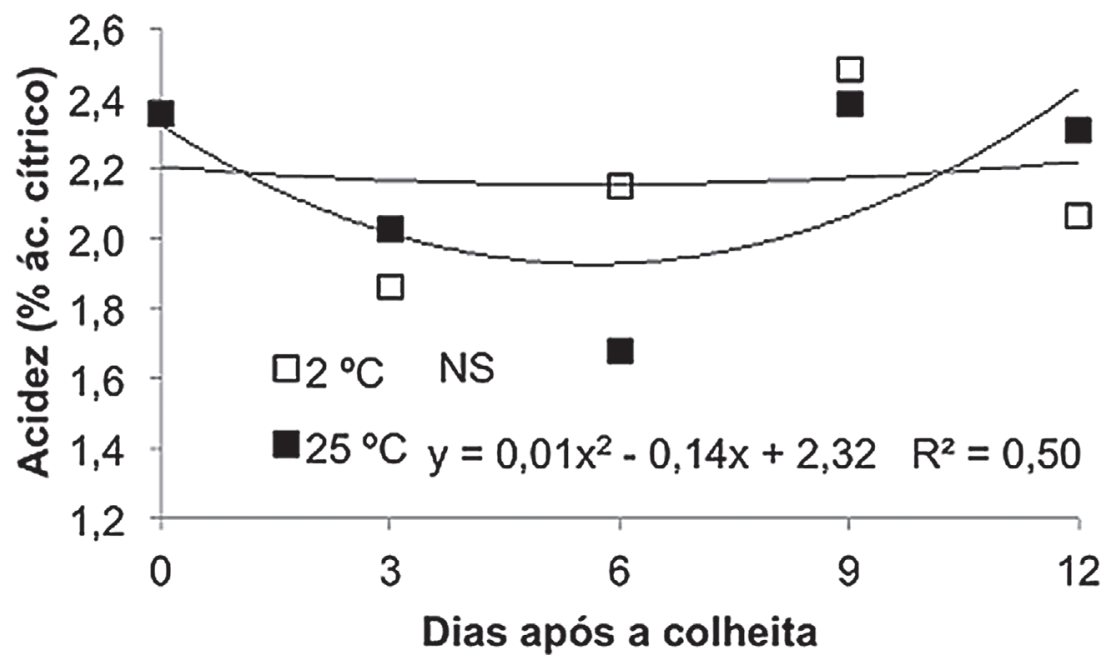

Figura 3. Valores médios de acidez titulável (\% ácido cítrico) dos frutos de araçazeiro-vermelho, em diferentes períodos $(0,3$, 6, 9 e 12 dias $)$ e temperaturas de armazenamento $\left(2^{\circ} \mathrm{C}\right.$ e $\left.25^{\circ} \mathrm{C}\right)$. CAV/UDESC, Lages, 2017.

na acidez dos frutos de $P$. cattleyanum. De acordo com Chitarra \& Chitarra (2005) o teor de ácidos orgânicos diminui com a maturação das frutas, em decorrência do processo respiratório ou de sua conversão em açúcares. No entanto, pode ocorrer um pequeno aumento no teor de ácidos orgânicos com o aumento da maturação. A diminuição da acidez com a maturação dos produtos vegetais pode ser justificada pelo consumo do próprio vegetal, na tentativa de este se manter em seu estado inicial (Rinaldi et al. 2005). No trabalho de Brunini et al. (2004) os teores de acidez titulável de frutos de jabuticaba variaram de 0,75 a $1,18 \mathrm{~g}$ de ácido cítrico $100 \mathrm{~g}^{-1}$ de polpa, durante o armazenamento refrigerado $\left(11^{\circ} \mathrm{C}\right)$ e de 0,14 a $1,16 \mathrm{~g}$ de ácido cítrico $100 \mathrm{~g}^{-1}$ de polpa, durante o armazenamento em condições ambiente. Percebem-se, comparativamente a este trabalho que, frutos de araçazeirovermelho são mais ácidos que frutos de jabuticabeira, seja em ambiente refrigerado $\left(2^{\circ} \mathrm{C}\right)$ ou em temperatura ambiente $\left(25^{\circ} \mathrm{C}\right)$, valores estes que variaram de 1,70 a $2,50 \mathrm{~g}$ de ácido cítrico $100 \mathrm{~g}^{-1}$ de polpa.

Quanto à relação sólidos solúveis/acidez titulável de araçásvermelhos, observou-se uma regressão linear crescente para frutos submetidos ao armazenamento de $2^{\circ} \mathrm{C}$, onde se observou o valor inicial de 4,5 e valor de 5,70 ao final de 12 
dias de armazenamento refrigerado (Figura 4). Observouse uma regressão quadrática para frutos submetidos ao armazenamento de $25^{\circ} \mathrm{C}$, no qual o valor máximo da relação ao sexto dia foi de 6,13. A partir do sexto dia observouse queda nos valores médios até o final do período de armazenamento.
A relação sólidos solúveis/acidez titulável é uma das formas mais utilizadas para a avaliação do sabor e dá uma boa ideia do equilíbrio entre esses dois componentes (Chitarra \& Chitarra, 2005). Em trabalho conduzido por, Cia et al. (2007) onde avaliaram frutos de amora de diferentes cultivares (Guarani e Caingangue) armazenados em diferentes

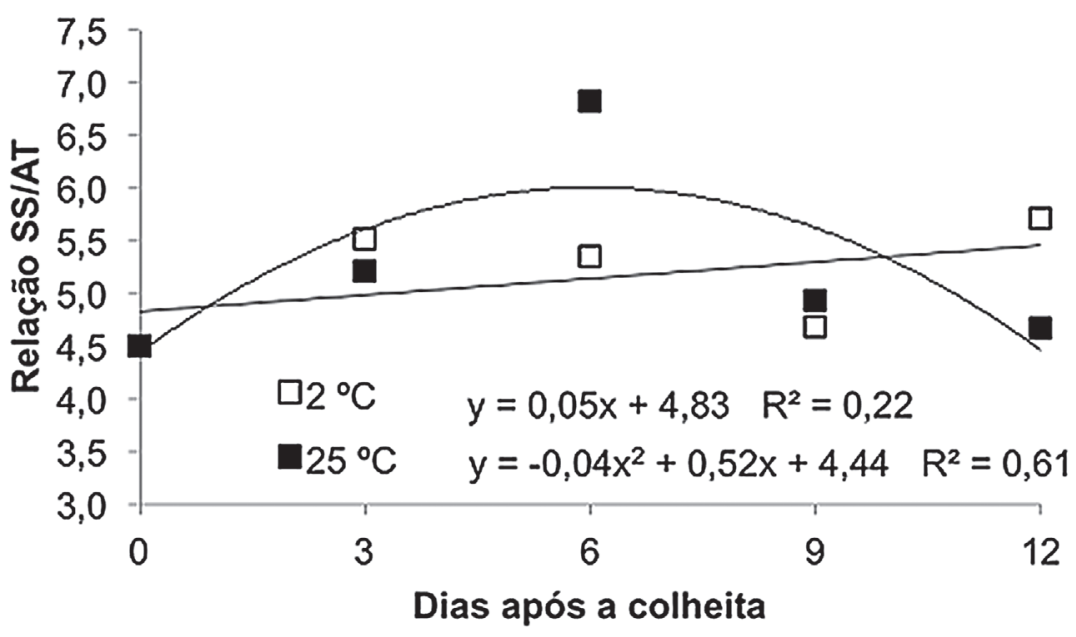

Figura 4. Relação sólidos solúveis/acidez titulável (SS/AT) dos frutos de araçazeiro-vermelho, em diferentes períodos (0, 3, 6, 9 e 12 dias) e temperaturas de armazenamento $\left(2{ }^{\circ} \mathrm{C}\right.$ e $\left.25^{\circ} \mathrm{C}\right)$. CAV/UDESC, Lages, 2017.

temperaturas, verificaram que sob refrigeração a $5^{\circ} \mathrm{C}$ e a $90 \%$ de umidade relativa não há diferenças na relação sólidos solúveis/acidez total titulável. No entanto, após nove dias de armazenamento, frutos da cv. Guarani mantidos sob condição ambiente e sob refrigeração a $5^{\circ} \mathrm{C}$, apresentavam menor relação sólidos solúveis/acidez titulável. Tal resultado implica em dizer que, mesmo cultivares de diferentes espécies apresenta comportamento distinto quanto à relação sólidos solúveis/acidez titulável.

Com relação ao $\mathrm{pH}$, em ambas as temperaturas avaliadas observou-se um comportamento quadrático. No entanto, à temperatura de $2^{\circ} \mathrm{C}$ observou-se um comportamento quadrático com ponto de mínima em 3,17 e, à temperatura de $25^{\circ} \mathrm{C}$, observou-se um comportamento quadrático com ponto de máxima em 3,21 (Figura 5).

Outros autores verificaram em $P$. guineense, valores próximos de $\mathrm{pH}$ aos deste trabalho, 3.0 (Franco, 1999), 3.99 na polpa e 3,76 na casca de araçá (Damiani et al. 2011). Os resultados obtidos, não corroboram com outro tipo de Myrtaceae ( $E$. dysenterica), pois, de acordo com Carneiro et al. (2015), frutos de cagaita armazenados em temperatura de $5^{\circ} \mathrm{C}$ ou $25^{\circ} \mathrm{C}$, não sofrem alteração no valor do $\mathrm{pH}$ ao longo de 5 dias de armazenamento pós-colheita. A capacidade-tampão de alguns sucos, permite que, ocorram grandes variações na acidez titulável, sem variações apreciáveis no $\mathrm{pH}$, além da regulação da atividade enzimática e respiratória dos tecidos (Chitarra \& Chitarra, 2005).

O teor de vitamina $\mathrm{C}$, em ambas as temperaturas de armazenamento, apresentou regressão quadrática, onde, frutos submetidos à temperatura de $2^{\circ} \mathrm{C}$ apresentaram menor teor de vitamina $\mathrm{C}$ aos sete dias de armazenamento, com teor de $17,23 \mathrm{mg} 100 \mathrm{~g}^{-1}$ polpa. Em condições de armazenamento a $25^{\circ} \mathrm{C}$, observou-se menor teor de vitamina $\mathrm{C}$ aos seis dias, com teor de $26,69 \mathrm{mg}^{100 \mathrm{~g}^{-1}}$ polpa (Figura 6).

Estudos efetuados por Raseira e\& Raseira (1996), em frutos maduros de cinco populações de $P$. cattleyanum, mostraram variação no teor de vitamina C, de 41,19 a 111,67mg $100 \mathrm{~g}^{-1}$ polpa. Em estudo conduzido por Giacobbo et al. (2008), com dois grupos de araçás, vermelho e amarelo, os autores observaram que frutos de araçá-vermelho apresentaram maior teor de vitamina $\mathrm{C}$ na polpa (44mg $100 \mathrm{~g}^{-1}$ ) comparativamente ao grupo de araçá-amarelo (27mg $\left.100 \mathrm{~g}^{-1}\right)$. Estes mesmos autores comparam frutos de araçá com outras frutíferas e referenciaram que os teores de vitamina $C$ encontrados no araçá são similares à grande maioria das frutíferas. 


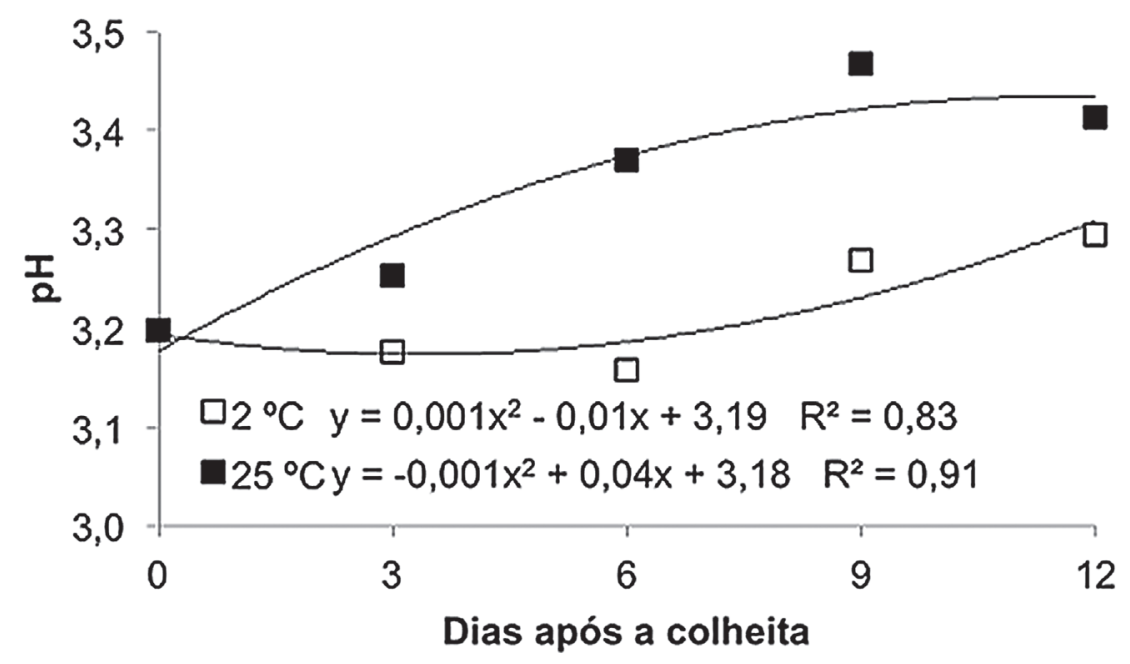

Figura 5. Valores de $\mathrm{pH}$ dos frutos de araçazeiro-vermelho, em diferentes períodos (0, 3, 6, 9 e 12 dias) e temperaturas de armazenamento $\left(2^{\circ} \mathrm{C}\right.$ e $\left.25^{\circ} \mathrm{C}\right)$. CAV/UDESC, Lages, 2017.

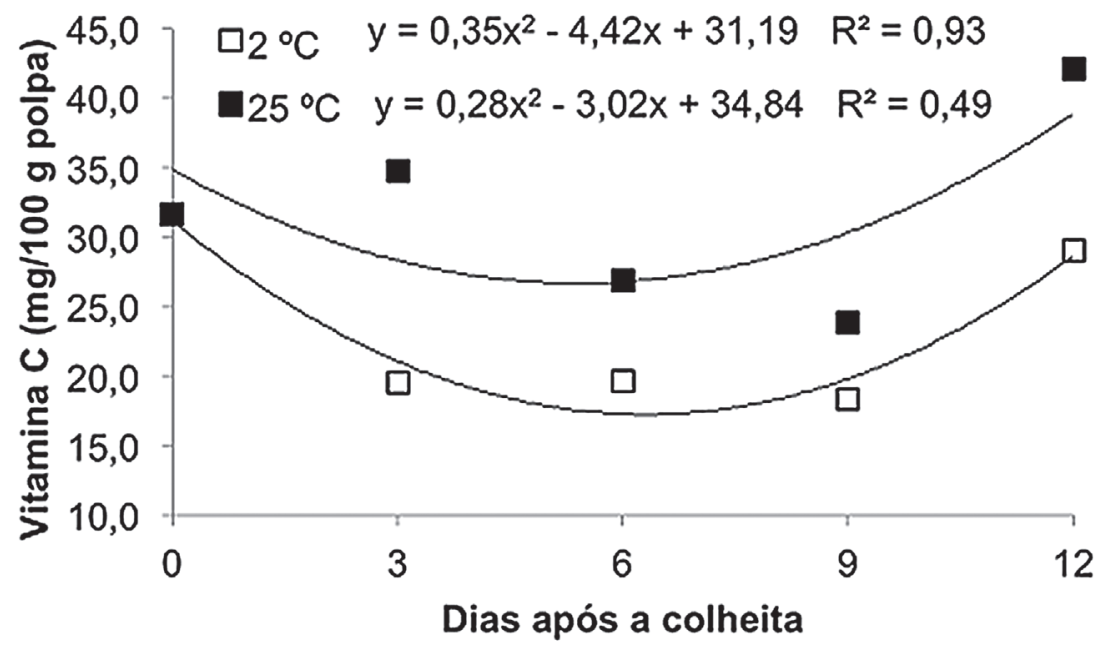

Figura 6. Teores de vitamina $\mathrm{C}$ ( $\mathrm{mg}$ de ácido ascórbico/100 $\mathrm{g}$ polpa) dos frutos de araçazeiro-vermelho, em diferentes períodos $(0,3,6,9$ e 12 dias $)$ e temperaturas de armazenamento $\left(2^{\circ} \mathrm{C}\right.$ e $\left.25^{\circ} \mathrm{C}\right)$. CAV/UDESC, Lages, 2017.

Ainda, neste mesmo trabalho, os autores relataram que o araçá tem teores inferiores ao da groselha preta e da goiaba; porém apresenta teores superiores à maçã e ao limão. Conforme Vieira et al. (2006), oOs frutos do araçazeiro são ricos em vitamina $C$ (três vezes maior do que a laranja). Conforme relato de Parra-Coronado (2014), verifica-se com a espécie $P$. guajava, que à medida que transcorre o período pós-colheita aumenta-se a perda de massa, o teor de sólidos solúveis e o valor de $\mathrm{pH}$, em contrapartida, diminui-se a firmeza do fruto e o ângulo hue ${ }^{\circ}$. Ainda, que os valores de acidez titulável e o conteúdo de ácido ascórbico se apresentam muito variáveis, ora diminuem, ora aumentam.

Pode-se dizer que, assim como outras frutas, a composição química dos frutos de araçazeiro-vermelho, pode variar de acordo com as chuvas, altitude, clima e solo nas regiões onde são colhidas (Caldeira et al. 2004), e também, de acordo com a origem do seu material genético, período de 
produção e maturação, com todas as características que influenciam a sua composição e valor nutricional (Bezerra et al. 2006).

Com a realização deste trabalho, pode-se aferir que, o uso de refrigeração a $2^{\circ} \mathrm{C}$, por até 12 dias, apresenta-se como uma alternativa de conservação de araçás-vermelhos, mantendose as principais características físico-químicas dos frutos.

Conflitos de interesses: O manuscrito foi preparado e revisado com a participação de todos os autores, quem declaramos que não existe conflito de interesses que ponha em risco a validez dos resultados apresentados.

\section{BIBLIOGRAFIAS}

1. ABREU, C.M.P.; CARVALHO, V.D.; GONÇALVES, N.B. 1998. Cuidados pós-colheita e qualidade do abacaxi para exportação. Informe Agropecuário (Brasil). 19(195):70-72.

2. AMARANTE, C.V.T.; STEFFENS, C.A.; ESPÍNDOLA, B.P. 2009. Preservação da qualidade pós-colheita de araçá-vermelho através do tratamento com 1-metilciclopropeno e do acondicionamento em embalagens plásticas sob refrigeração. Rev. Bras. Fruticult. (Brasil). 31(4):969-976.

3. BEZERRA, J.E.F.; LEDERMAN, I.E.; SILVA JÚNIOR, J.F.; PROENÇA, C.B. 2006. Araçá. In: Vieira, R.F., Agostini Costa, T.S., Silva, D.B., Sano, S., Ferreira, F.F. (Org.). Frutas Nativas da Região Centro Oeste do Brasil. Embrapa Inform. Tecnológica (Brasil), Brasília., Brasil. p.42-62.

4. BRASIL. Ministério do Meio Ambiente. Biodiversidade Brasileira. 2017. Disponível em: http://www.mma. gov.br/biodiversidade/biodiversidade-brasileira (acesso em 20/09/2017).

5. BRUNINI, M.A.; OLIVEIRA, A.L.; SALANDINI, C.A.R.; BAZZO, F.R. 2004. Influência de embalagens e temperaturas no armazenamento de Jabuticabas (Myrciaria jabuticaba (Vell) Berg) cv. 'SABARÁ'. Ciência Tecnologia de Alimentos (Brasil). 24(3):378383.

6. BUSO-RAMOS, M.M.; FEIRIA, S.N.B.; BONI, G.C.; HÖFLING, J.F. 2017. Psidium cattleianum (Myrtaceae) as a natural antimicrobial source against oral bacteria. Adv Dent \& Oral Health. 4(5):1-3.

7. CALDEIRA, S.D.; HIANE, P.A.; RAMOS, M.I.L.; RAMOS FILHO, M.M. 2004. et al. 2004. Caracterização físico-quimica do araça (Psidium guineense Sw.) e do tarumã (Vitex cymosa Bert.) do Estado do Mato Grosso do Sul. Boletim CEPPA. v. 22(n. 1): p. 145154.

8. CARNEIRO, J.O.; SOUZA, M.A.A.; RODRIGUES, Y.J.M.R.; MAPELI, A.M. 2015. Efeito da temperatura e do uso de embalagem na conservação pós-colheita de frutos de cagaita (Eugenia dysenterica DC.). Rev. Bras. Fruticult. 37(3):568-577.

9. CENCI, S.A. 2006. Boas Práticas dePós-colheita de Frutas e Hortaliças na Agricultura Familiar. In: Fenelon do Nascimento Neto. (Org.). Recomendações Básicas para a Aplicação das Boas Práticas Agropecuárias e de Fabricação na Agricultura Familiar. 1a ed. Brasília: Embrapa Inform. Tecnológica, p.67-80.

10. CIA, P.; BRON, I.U.; VALENTINI, S.R. de T.; PIO, R.; CHAGAS, E.A. 2007. Atmosfera modificada e refrigeração para conservação pós-colheita da amora-preta. Bioscience J. (Brasil). 23(1):11-16.

11. CHITARRA, M.I.F.; CHITARRA, A.B. 2005. Pós-colheita de frutas e hortaliças. Edit. UFLA (Brasil). 785p.

12. COSTA, M.A.P.C.; SOUZA, F.L.C.; LUNA, J.V.U.; CASTELLEN, M.S.; ALMEIDA, W.A.B.; SILVA, S.A.; DANTAS, A.C.V.L. 2009. Conservação de fruteiras potenciais para o nordeste brasileiro. Tópicos em Ciências Agrárias (Brasil). 1(1):1-13.

13. DAMIANI, C.; VILAS BOAS, E.V.B.; ASQUIERI, E.R.; LAGE, M.E.; OLIVEIRA, R.A.; SILVA, F.A.; PINTO, D.M.; RODRIGUES, L.J.; SILVA, E.P.; PAULA, N.R.R. 2011. Characterization of fruits from the savanna: Araça (Psidium guinnensis Sw.) and Marolo (Annona crassiflora Mart.). Ciência e Tecnologia de Alimentos, Campinas, (Brasil). 31(3): 723-729.

14. DREHMER, A.M.F.; AMARANTE, C.V.T. do. 2008. Conservação pós-colheita de frutos de araçávermelho em função do estádio de maturação e temperatura de armazenamento. Rev. Bras. Fruticult. 30(2):322-326.

15. FALEIRO, J.H.; GONÇALVES, R.C.; SANTOS, M.N.G.; SILVA, D.P.; NAVES, D.P.L.F.; MALAFAIA, G. 2016. The chemical featuring, toxicity, and antimicrobial activity of Psidium cattleianum (Myrtaceae) Leaves. New Journal of Science. 2016:1-8.

16. FRANCO, G. 1999. Tabela de composição química dos alimentos. 9. ed. São Paulo: Atheneu, 1999. 
17. FRANZON, R.C.; CAMPOS, L.Z. de O.; PROENÇA, C.E.B.; SOUSA-SILVA, J.C. 2009. Araçás do Gênero Psidium: principais espécies, ocorrência, descrição e usos. Documentos/ Embrapa Cerrados. Planaltina, DF. (Brasil). Disponível em: https://www.embrapa.br/ busca-de-publicacoes/-/publicacao/697560/aracasdo-genero-psidium-principais-especies-ocorrenciadescricao-e-usos (acesso em 20/09/2017).

18. GIACOBBO, C.L.; ZANUZO, M.; CHIM, J.; FACHINELLO, J.C. 2008. Avaliação do teor de vitamina $C$ em diferentes grupos de araçá-comum. Rev. Bras. Agrociência (Brasil).14(1):155-159.

19. LEDERMAN, I.E.; SILVA, M.F.F da; ALVES, M.A.; BEZERRA, J.E.F. 1997. Selection of superior genotypes of Brazilian guava (Psidium guineense, Swartz) in the Coastal Wood Forest Region of Northeast Brazil. Acta Horticult. (Holanda). 452(1):95-100.

20. MACHADO, A.; CONCEIÇÃO, A.R. 2003. Programa estatístico WinStat - Sistema de Análise Estatística para Windows, versão 2.0. Edit. UFPel (Brasil). 5p.

21. MACHADO, N.P.; COUTINHO, E.F.; CAETANO, E.R. 2007. Embalagens plásticas e refrigeração na conservação pós-colheita de jabuticabas. Rev. Bras. Fruticult. 29(1):166-168.

22. MOTA, W.F.; SALOMÃO, L.C.C.; PEREIRA, M.C.F.; CECON, P.R. 2002. Influência do tratamento póscolheita com cálcio na conservação de jabuticabas. Rev. Bras. Fruticult. 24(1):49-52.

23. PARRA-CORONADO, A. 2014. Maduración y comportamiento poscosecha de la guayaba (Psidium guajava L.). Una revisión. Rev. Col. Ciencias Hortícolas (Colômbia). 8(2):314-327.

24. PINTO, S.A.A.; BIANCA, S.; DURIGAN, J.F.; SILVA, A. 2000. Características químicas do araçá (Psidium cattleyanum, Sabine) em diferentes estádios de maturação. In: Congresso Brasileiro de Fruticultura, 16. Fortaleza, CE. Resumos... Fortaleza: SBF: Embrapa Agroindústria Tropical. Disponível em CDROM.

25. RASEIRA, M. do C.B.; RASEIRA, A. 1996. Contribuição ao estudo do araçazeiro, Psidium cattleyanum. Pelotas: EMBRAPA-CPACT. 95p.

26. RINALDI, M. M.; BENEDETTI, B.C.; CALORE, L. 2005. Efeito da embalagem e temperatura de armazenamento em repolho minimamente processado. Food Science and Technology (Brasil). 25(3):480-486.

27. SCUR, M.C.; PINTO, F.G.; PANDINI, J.A.; COSTA, W.F.; LEITE, C.W.; TEMPONI, L.G. 2016. Antimicrobial and antioxidant activity of essential oil and different plant extracts of Psidium cattleianum Sabine. Braz. J. Biology (Brasil). 76(1):101-108.

28. STROHECKER, R.L.; HENNING, H.M. 1967. Análises de Vitaminas: Métodos comprobados. Edit. Paz Montalvo (Espanha). 428p.

29. VIEIRA, R.F.; COSTA, T.S.A.; SILVA, D.B.; FERREIRA, F.R.; SANO, S.M. 2006. Frutas nativas da região Centro-Oeste. Brasília: Embrapa Recursos Genéticos e Biotecnologia, 320p.

30. ZAPPI, D.C.; FILARDI, F.L.R.; LEITMAN, P.; SOUZA, V.C.; WALTER, B.M.T.; PIRANI, J.R.; MORIM, M.P.; QUEIROZ, L.P.; CAVALCANTI, T.B.; MANSANO, V.F.; FORZZA, R.C. 2015. Growing knowledge: an overview of Seed Plant diversity in Brazil. Rodriguésia (Brasil). 66(4):1085-1113.

Recibido: Julio 27 de 2017

Aceptado: Octubre 12 de 2017

Cómo citar:

Muniz, J.; Pelizza, T.R.; Fernandes de Lima, A.P.; Gonçalves, M.J.; Rufato. L. 2017. Qualidade pós-colheita de araçá-vermelho. Rev. U.D.C.A Act.\& Div. Cient. 20(2): 311-319. 